\title{
ANÁLISE, A PARTIR DE IMAGEM LANDSAT 8, DE ILHAS DE CALOR NA CIDADE BRASILEIRA DE CÁCERES/MT
}

\author{
Alexandre Webber Perlandim Ramos ${ }^{(a)}$, Sandra Mara Alves da Silva Neves ${ }^{(b)}$, Géssica de Jesus \\ Oliveira Silva ${ }^{(\mathrm{c})}$
}

(a)Curso de Geografia/Faculdade de Ciências Humanas, Universidade do Estado de Mato Grosso, E-mail: webber.unemat@gmail.com

(b)Curso de Geografia/Faculdade de Ciências Humanas, Universidade do Estado de Mato Grosso, E-mail:; ssneves@unemat.br

webber.unemat@gmail.com; ssneves@unemat.br; gessica.unemat@gmail.com

(c)Curso de Geografia/Faculdade de Ciências Humanas, Universidade do Estado de Mato Grosso, E-mail: gessica.unemat@gmail.com

\section{Eixo: CLIMATOLOGIA EM DIFERENTES NÍVEIS ESCALARES: MUDANÇAS E VARIABILIDADES}

\begin{abstract}
Resumo
No meio urbano o uso de materiais de alta inércia térmica e a constante supressão da vegetação resultam em uma morfologia urbana com características contrárias à recomendação de conforto térmico e com elevado acúmulo de calor. O objetivo deste estudo é análisar as ilhas de calor na cidade brasileira de Cáceres/MT, a partir de imagem do satélite Landsat 8, do ano de 2016, processadas nos softwares SPRING e ArcGis. Verificou-se na urbe de Cáceres que há formação de ilhas de calor, situadas nos bairros centrais e adjacentes, principalmente em áreas com solo exposto, apresentando temperaturas mais elevadas em relação aos próximo a orla e em áreas não urbanizadas. Concluiu-se que é necessário contemplar no planejamento urbano de Cáceres estratégias que visem fomentar a arborização nas áreas com elevada temperatura superficial para que os efeitos deste fenômeno sejam amenizados, refletindo na melhoria da qualidade ambiental urbana.
\end{abstract}

Palavras chave: urbanização, geotecnologias, Pantanal.

\section{Introdução}

Nas últimas décadas o Brasil vem passando por acelerado processo de urbanização, atualmente mais de 80\% da sua população reside em áreas urbanas (IBGE, 2017), o que vem gerando preocupações em relação à qualidade de vida nas cidades, visto que o crescimento populacional, aliado a falta de planejamento e investimentos urbanos, tem acarretado numa série de consequências negativas.

Diversas atividades antrópicas, como por exemplo, a ampla utilização de veículos automotores, têm causado mudanças na composição química atmosférica por meio de um contínuo aumento na concentração de gases com efeitos poluentes, como o dióxido de carbono. Somadas a esses processos, mudanças na superfície terrestre, como o processo de urbanização, que tem como efeito a substituição da 
cobertura vegetal por construções, têm aumentado de forma ponderosa a impermeabilização dos solos e a propagação de calor para a atmosfera.

Diante desses fatos Souza (2004) acresce que cidades mal planejadas sofrem graves problemas com o fenômeno ilha de calor, que ocorrem em locais com elevada quantidade de construções e baixa concentração de áreas verdes. Este aumento da temperatura em diversas áreas urbanas vem prejudicando a saúde da população devido a maior suscetibilidade de problemas à saúde, como desidratação, oscilação de pressão arterial, problemas respiratórios, renais, dentre outros.

Nesse viés, o uso geotecnologias como o sensoriamento remoto e os Sistemas de Informações Geográficas (NICHOL, 1996), são ferramentas que possibilitam a analise de tal fenômeno, visto que agregam informações espaciais multivariadas, que podem ser ponderadas sob uma ótica dinâmica.

\section{Objetivo}

Neste estudo o objetivo é analisar, a partir do o fenômeno de ilhas de calor na área urbana de Cáceres/MT, visando à geração de subsídios que contribua para o planejamento e a conservação ambiental.

\section{Máteriais e Métodos}

\section{1. Área de Estudo}

A cidade de Cáceres/MT está localizada na margem esquerda do rio Paraguai (Figura 1), compreendendo uma área de 68,95 km² (COCHEV et al., 2010) com uma população urbana residente de 76.568 mil habitantes (IBGE, 2017). 


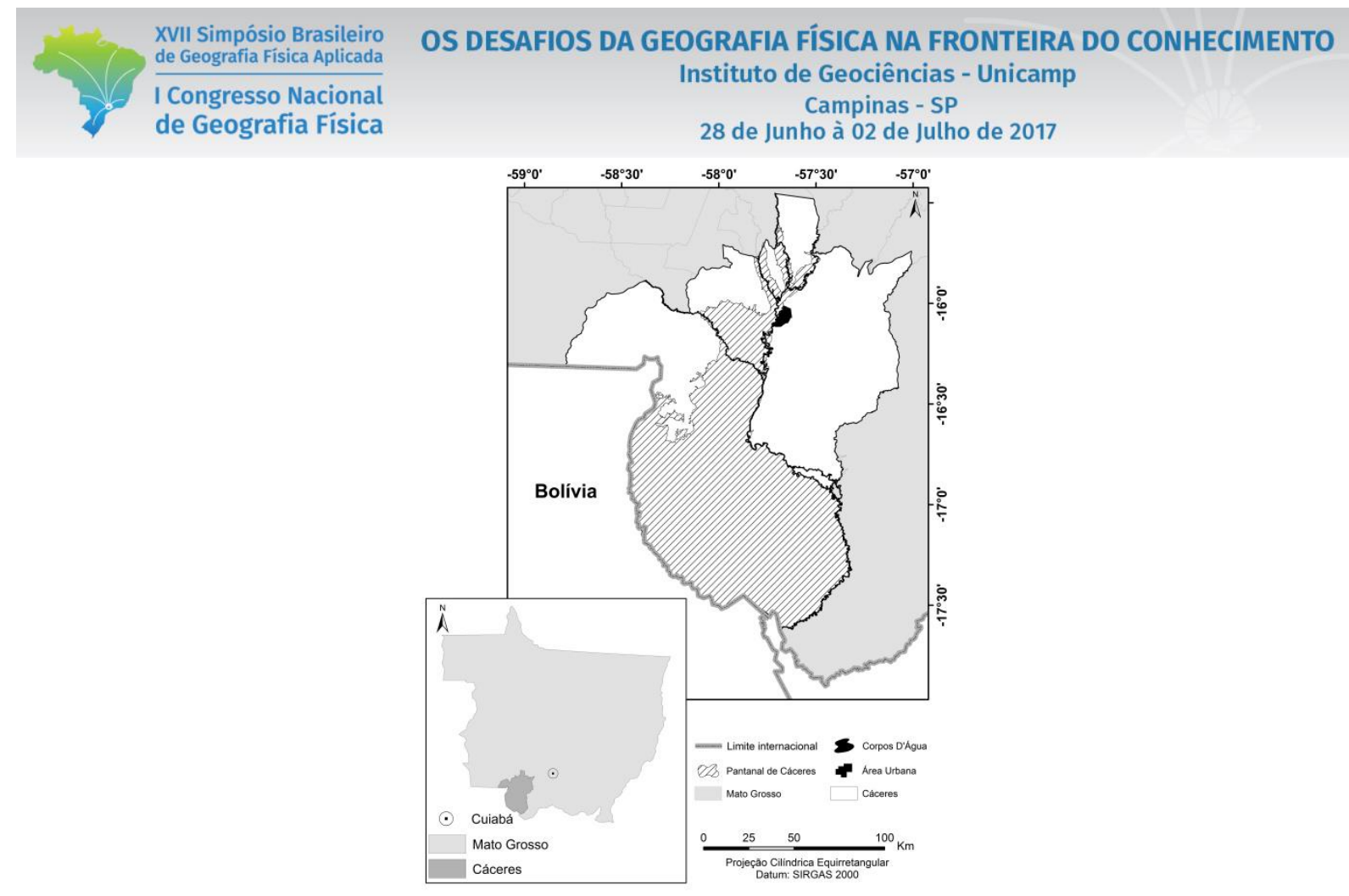

Figura 1 - Área Urbana de Cáceres-MT. Fonte: Os Autores

\subsection{Procedimentos Metodológicos}

Utilizou-se imagens do satélite Landsat 8, sensor Operational Land Imager (OLI) do ano de 2016, referente à órbita 227, ponto 071, obtidas no sítio do United States Geological Survey (USGS, 2013).

A imagem do satélite para definição dos usos da terra foi recortada, segmentada e classificada no software Spring, versão 5.3 (CÂMARA et al., 1996). Sendo que os limiares da segmentação foram similaridade de 100 e área de 100 (pixel com semelhanças) e o método de crescimento de regiões, com interpolador Bhattacharya.

Para a geração do mapa termográfico foi utilizado o software ArcGis 10.5 (ESRI, 2017) utilizando-se da banda 10 (infravermelho termal) do satélite Landsat 8, sensor Operational Land Imager (OLI) do ano de 2016, referente à órbita 227, ponto 071, obtidas no sítio do United States Geological Survey (USGS, 2013). Os procedimentos de recorte e conversão dos níveis de cinza para radiância foi dado por meio da fórmula 1 (COELHO; CORRÊA, 2013).

$L \lambda=M L * Q c a l+A L$

Onde:

$\mathrm{L} \lambda=$ Radiância Espectral do sensor de abertura em Watts $/\left(\mathrm{m}^{2} \mathrm{sr} \mu \mathrm{m}\right)$; 
$\mathrm{ML}=$ Fator multiplicativo de redimensionamento da banda $10=3.3420 \mathrm{E}-04$;

$\mathrm{AL}=$ Fator de redimensionamento aditivo especifico da banda $10=0.10000 ;$ Qcal $=$ Valor quantizado calibrado pelo pixel em DN = Imagem banda 10.

Os valores de radiâncias foram obtidos através da aplicação da fórmula 2 (COELHO; CORRÊA, 2013) visando a aquisição dos diferentes níveis de temperatura das imagens.

$T=K 2 /(\operatorname{in}(K 1 / L \lambda+1))$

Sendo: T: Temperatura efetiva no satélite em Kelvin (K);

K2: Constante de calibração $2=1.321 .08(\mathrm{~K})$;

K1: Constante de calibração $1=774.89(\mathrm{~K})$;

L $\lambda$ : Radiância espectral em Watts/ (W m-2sr -1).

Após a conclusão das etapas apresentados os valores de temperatura em Kelvin foram convertidos em graus Celsius $\left({ }^{\circ} \mathrm{C}\right)$ através da fórmula 3 .

$T c=T k-273,15$

Onde:

Tc: Temperatura em Celsius

Tk: Temperatura em Kelvin.

Para o estabelecimento das análises e discussão os resultados obtidos foram confrontados com a literatura referente ao tema.

\section{Resultados e Discussão}

A área de estudo apresentou quatro classes temáticas, sendo duas pertencente a categoria uso antrópico, uma relativa às formações vegetais e a uma de água (Figura 2). 


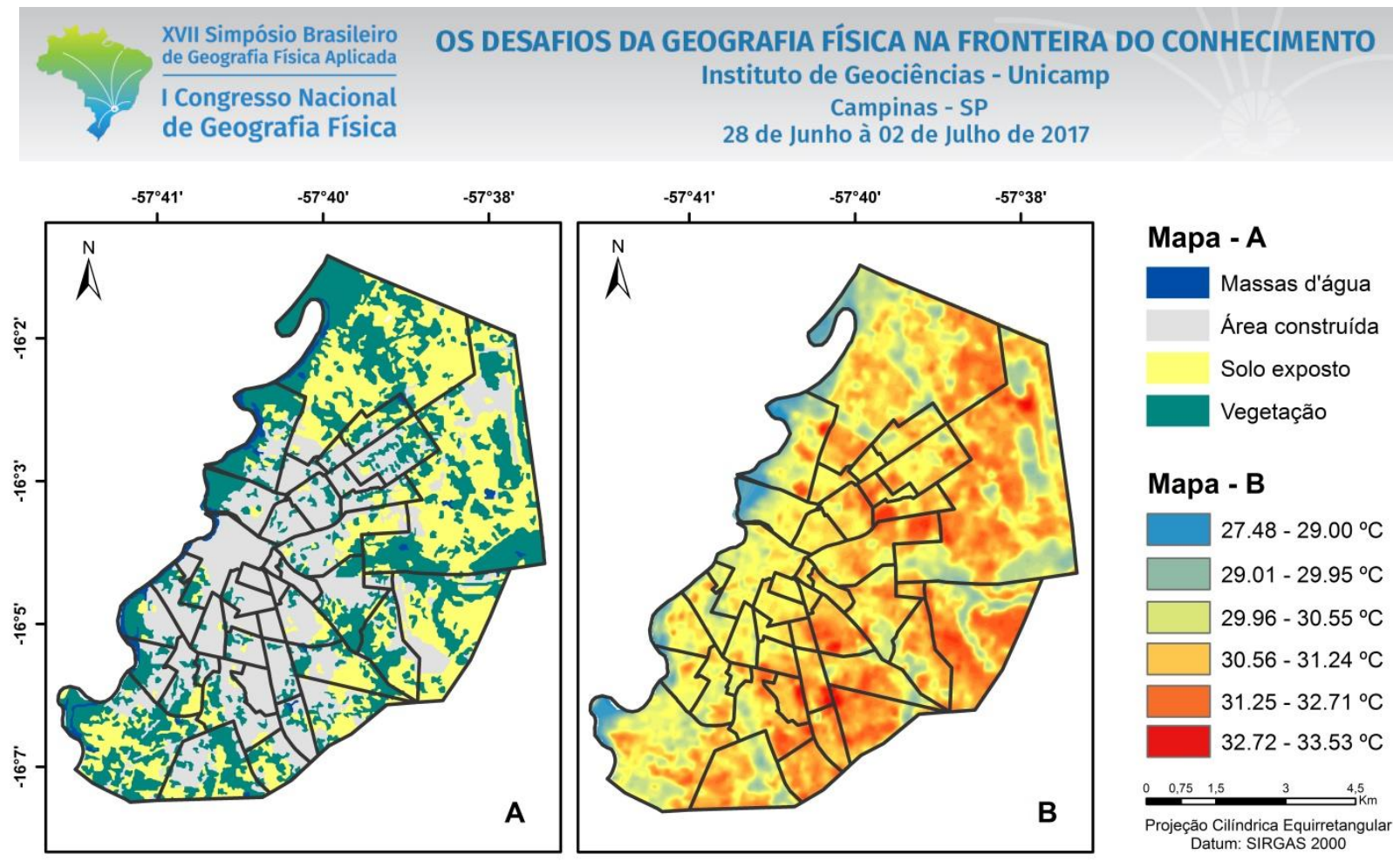

Figura 2 - Usos e cobertura vegetal da terra (A) - Temperatura Superficial (B). Fonte: Os Autores (2017).

A cidade encontra-se estabelecida na margem esquerda do Rio Paraguai, disposta no sentido N a NO predomina a presença das classes água, onde observou-se as menores temperaturas, que variam entre $27.48{ }^{\circ} \mathrm{C}$ a $29.00{ }^{\circ} \mathrm{C}$. Tais valores são resultantes da forte presença de umidade encontradas nesses ambientes, uma vez essas áreas possuem grande capacidade de absorção de radiação solar, Alcântara et al. (2011) corrobora com o exposto ao afirmar que parte da energia que é recebida nesses locais é convertida em calor latente e emitida a atmosfera pelo processo de evaporação da água.

As áreas construídas, com presença de solo exposto, apresentaram temperaturas mais elevadas resultantes da substituição da cobertura vegetal. A impermeabilização do solo por materiais, como asfalto e concreto, resultantes da redução de áreas vegetadas alteram as propriedades térmicas, radiativas da área urbana (OKE; MAXWELL, 1975).

As áreas dos bairros com vegetação apresentaram as menores temperaturas, decorrente do efeito de sombreamento das superfícies e pelos altos níveis de fluxo de calor latente, o que segundo Oke (1982) é devido a uma maior quantidade de água disponível para os processos de evaporação e evapotranspiração.

\section{Conclusão}

Concluiu-se que é necessário contemplar no planejamento urbano de Cáceres estratégias que visem fomentar a arborização nas áreas com elevada temperatura superficial para que os efeitos deste fenômeno sejam amenizados, refletindo na melhoria da qualidade ambiental urbana. 
As técnicas utilizadas nesta pesquisa, pautadas nas geotecnologias (SIG e Sensorimento Remoto), se mostraram eficientes e necessárias, devido a carência de disponibilidade dados meteorológicos para várias extensões do País, constituindo uma alternativa para execução pesquisas realizadas na área da Geografia Física.

\section{Referências bibliográficas}

ALCÂNTARA, E. H.; STECH, J. L.; LORENZZETTI, J. A.; NOVO, E. M. L. M.; SOUZA, A.F. Estimativa dos fluxos de calor sensível e latente na superfície da água do reservatório de Itumbiara (GO) por meio de dados MODIS/Terra. In: Simpósio Brasileiro de Sensoriamento Remoto, 15., 2011, Curitiba. Anais... São José dos Campos: INPE, 2011. p. 5185-5192.

COCHEV, J. S.; NEVES, S. M. A. S.; NEVES, R. J. Espaço urbano de Cáceres/MT analisado a partir de imagens de sensoriamento remoto e SIG. Revista GeoPantanal, v. 5, n. 8, p. 145-160, 2010.

CÂMARA, G.; SOUZA, FREITAS, R. C. M.; GARRIDO U. M. J. SPRING: Integrating remote sensingand GIS by object oriented data modelling. Computers \& Graphics, v. 20, n. 3, p. 395-403, 1996.

COELHO, A. L. N.; CORREA, W. S.C. Temperatura de Superfície Celcius do Sensor TIRS/LandSat - 8: metodologia e aplicações. In: Revista Geográfica Acadêmica, v. 7, n. 1, p. 31-45, 2013.

ESRI. ArcGis 10.5. Environmental Systems Research Institute. Redlands, CA., 2017.

IBGE. Instituto Brasileiro de Geografia e Estatística. Sinopse do Censo Demográfico 2010. Disponível em: http:// www.censo2010.ibge.gov.br/sinopse/index.php?uf=51\&dados=0. Acessado em: 27 mai. 2016.

MATO GROSSO (Estado). Secretaria de Estado de Planejamento e Coordenação Geral. Plano de Longo Prazo de Mato Grosso: macro-objetivos, metas globais, eixos estratégicos e linhas estruturantes. In: PRADO, J. G. B.; BertChIEli, R.; OliveIRA, L. G. (Orgs). Plano de Longo Prazo de Mato Grosso. Cuiabá/MT: Central de Texto, 2012. 108p.

NICHOL, J. E. High-Resolution surface temperature patterns related to urban morphology in a tropical city: a satellite-based study. Journal of Applied Meteorology, v. 35, p. 135-146. 1996.

OKE, T. R.; MAXWELL, G. B. Urban heat island dynamics in Montreal and Vancouver. Atmospheric Environment, Oxford, v.9, p.191-200, 1975.

OKE, T. R. The energetic basis of the urban heat island. Quarterly Journal of the Royal Meteorological Society, Berks, v. 108, p.1-4, 1982.

USGS. United States Geological Survey, 2016. Disponível em: <http://landsat.usgs.gov>. Acesso em: 07 jul. 2013.

SOUZA, L. C. L. Ilhas de calor. Jornal Unesp, v. 18, n. 186, p. 11, 2004. 